\title{
PENGARUH KUALITAS PELAYANAN DAN KINERJA KARYAWAN TERHADAP KEPUASAN MAHASISWA PADA UNIVERSITAS ISLAM KALIMANTAN MUHAMMAD ARSYAD AL BANJARI BANJARMASIN \\ (Studi Kasus pada Kegiatan Penerimaan Mahasiswa Baru) \\ Siti Mardah \\ Universitas Islam Kalimantan Muhammad Arsyad Al Banjari Banjarmasin \\ sitimardah27@gmail.com
}

\begin{abstract}
This study aims to determine how much influence the quality of service and employee performance has on student satisfaction at the Islamic University of Kalimantan Muhammad Arsyad Al Banjari, especially in the New Student Admissions Counter for the 2019-2020 period. This study uses a sample size of 98 respondents using the slovin formula. . From this research, it is concluded that the variable $\mathrm{X} 1$ has a positive and insignificant effect on Variable $\mathrm{Y}$, so that $\mathrm{H} 1$ is rejected and for Variable $\mathrm{X} 2$ the results have a positive and significant effect on Variable $Y$, so that $\mathrm{H} 2$ is accepted. For the $\mathrm{F}$ test, the significance value is $0.000<0.005$ and the $\mathrm{F}$ value is calculated. $12.978>$ 3.09. So it can be concluded that $\mathrm{H} 3$ is accepted. The value of $\mathrm{R}$ Square is 0.472 , meaning that the simultaneous influence of variables $\mathrm{X} 1$ and $\mathrm{X} 2$ on variable $\mathrm{Y}$ is $47.2 \%$, and the remaining $52.8 \%$ is influenced by other variables outside the variable. that the author tested.
\end{abstract}

Keywords: Service Quality, Employee Performance, Student Satisfaction 


\section{PENDAHULUAN}

Seiring dengan perkembangan teknologi di jaman modern sekarang,setiap organisasi pemerintah maupun swasta baik yang bergerak dibidang barang atau jasa harus menggunakan tekhnologi informasi sebagai media atau sarana untuk mempermudah pelayanan dalam pekerjaan.Contoh penggunaan media internet untuk promosi secara online sangat dibutuhkan sekali.Perkembangan internet saat ini bukan hanya berfungsi sebagai media informasi,namun internet juga dapat dimanfaatkan untuk kepentingan bisnis yaitu sebagai bisnis online dengan menggunakan layanan berbasis website (Situmorang, 2012: 77).

Dalam layanan berbasis website tersebut banyak komponen-komponen penting didalamnya untuk mencapai kesuksesan dalam bisnis, salah satunya adalah kualitas pelayanan elektronik (E-Service Quality). Perusahaan yang memberikan e-service quality semakin tinggi kepada pelanggan maka akan menimbulkan customer satisfaction, dan dalam jangka waktu yang panjang tentunya akan menghasilkan customer loyalty.

Kondisi pasar yang semakin bergantung kepada smartphone, maka akan semakin banyak perusahaan e-commerce yang ikut memanfaatkan smartphone, seperti salah satunya adalah Universitas Islam Kalimantan Muhammad Arsyad Al Banjari Banjarmasin. Media ini digunakan universitas sebagai media untuk penerimaan mahasiswa baru secara online.Dimana tujuannya dari penggunaan media ini adalah untuk memberikan kemudahan kepada mahasiswa untuk mendaftar kuliah dikampus tersebut. Calon mahasiswa akan mudah mendaftarkan dirinya dimana saja dan kapan saja, serta pembayaran pendaftran juga mudah dilakukan bisa melalui mobile banking sesuai dengan bank yang sudah ditunjuk pihak universitas untuk bekerjasama.

Pihak Universitas melakukan upaya untuk meningkatkan kualitas pelayanan

dengan menggunakan sistem terintegrasi dan terekam secara online. Segala kegiatan 
pendaftaran dilakukan melalui website termasuk pembayarannya dilakukan melalui rekening universitas yang sudah atur sedemikian rupa oleh pihak IT.

Para calon mahasiswa bisa mendapatkan informasi mengenai seputar penerimaan mahasiswa baru melalui hotline yang ada di brosur di website.Hal ini akan mempermudah mereka untuk mendapatkan informasi yang diperlukan, sehingga mereka tidak perlu datang langsung ke kampus.Hal ini bisa menghemat waktu, tenaga dan juga biaya.

Selain meningkatkan kualitas pelayanan, pihak kampus juga berusaha meningkatkan kinerja karyawannnya, karena kinerja karyawan sangat berpengaruh bagi kesuksesan sebuah perusahaan. Kinerja atau performa karyawan yang bagus akan berbanding lurus dengan hasil baik dalam perkembangan bisnis perusahaan. Sebaliknya, kinerja yang buruk akan berdampak buruk pula pada perusahaan. Hasil performa karyawan ini dapat dilihat dari aspek kualitas, kuantitas, waktu kerja, dan kerja sama untuk mencapai tujuan yang sudah ditetapkan oleh perusahaan. Semuanya tergantung pada kuantitas dan waktu yang digunakan karyawan dalam menjalankan tugas. Faktor kinerja karyawan juga bisa dinilai dari waktu kerja, jumlah absen, keterlambatan, dan lamanya masa kerja.

Namun walaupun sudah ada tempat pengaduan secara online, tapi tetap saja masih ada calon mahasiswa yang merasa kurang puas dalam pelayanan tersebut.Hal ini dikeluhkan karena petugas customer service yang lambat merespone pertanyaan mereka, sehingga banyak pengguna merasa dirugikan. Hal ini tentunya akan berdampak negative kepada kepuasan pelanggan.

Pada e-comerce,e-loyality dipengaruhi oleh kepuasan yang konsumen terima atas jasa yang diberikan oleh website (Anderson dan Srinivasan, 2003). Dengan kata lain, jika kepuasan konsumen terhadap website tinggi, maka loyalitanya akan tinggi pula. Kartajaya (2006:25, p.25) menyatakan bahwa kualitas suatu offer atau suatu penawaran 
akhirnya tidak hanya ditentukan oleh product quality tetapi juga ditentukan oleh $e$ service quality, oleh karena itu peranan e-service quality makin penting. Pengaruh eservice quality terhadap loyalitas juga telah dibuktikan oleh hasil penelitian Sabihaini (2002) yang menyimpulkan bahwa peningkatan e-service quality akan memberikan dampak yang baik untuk meningkatkan loyalitas. Bloomer et al, (1998) mendapatkan eservice quality memiliki pengaruh langsung terhadap loyalitas akan mempengaruhi loyalitas melalui kepuasan.

Menurut Harmawanto (2012), e-service quality dianggap sebagai salah satu factor penting dari customer satisfaction, karena e-service quality merupakan aspek customer satisfaction yang sifatnya sulit ditiru karena menyangkut sikap dan perilaku anggota organisasi.

Parasurama et al., (2005:01) menyebutkan beberapa kelemahan yang masih ada pada transaksi online yaitu,"Konsumen tidak dapat menyelesaikan transaksi, produk tidak disampaikan tepat waktu atau sama sekali, email tidak terjawab,dan informasi yang diinginkan tidak bisa diakses."Hal ini memberikan tantangan tersendiri kepada perusahaan untuk terus meningkatkan kualitas layanan agar kepuasan pelanggan yang maksimal dapat terpenuhi.Fenomena yang telah dijelaskan tersebut mengindikasikan bahwa pengelolaan e-sevice saat ini melalui transaksi full online akan membawa banyak perubahan dalam dunia bisnis ke depannya.

Kotler (2012:2) mengemukakan bahwa terdapat hubungan yang erat antara $e$ service quality, cutomer satisfaction, dan profitabilitas perusahaan. Konsumen yang merasa kurang puas akan lebih banyak memberikan complain dari pada melakukan pembelian ulang (Cho et al., 2004: Cronin dan Taylor, 1992), sementara konsumen yang merasa puas kemungkinan besar bersedia terikat kepada satu penyedia layanan dan kemudian menjadi pelanggan yang setia (tian \& kek, 2004).

\section{TINJAUAWAN PUSTAKA}


Kualitas merupakan suatu kondisi dinamis yang berpengaruh dengan produk, jasa, manusia, proses dan lingkungan yang memenuhi atau melebihi harapan (Tjiptono, 2001). Sehingga definisi kualitas pelayanan dapat diartikan sebagai upaya pemenuhan kebutuhan dan keinginan konsumen serta ketepatan penyampaiannya dalam mengimbangi harapan konsumen (Tjiptono, 2007). Kualitas pelayanan (service quality) dapat diketahui dengan cara membandingkan persepsi para konsumen atas pelayanan yang nyata-nyata mereka terima / peroleh dengan pelayanan yang sesungguhnya mereka harapkan / inginkan terhadap atribut-atribut pelayanan suatu perusahaan. Jika jasa yang diterima atau dirasakan (perceived service) sesuai dengan yang diharapkan, maka kualitas pelayanan dipersepsikan baik dan memuaskan, jika jasa yang diterima melampaui harapan konsumen, maka kualitas pelayanan dipersepsikan sangat baik dan berkualitas.Sebaliknya jika jasa yang diterima lebih rendah daripada yang diharapkan, maka kualitas pelayanan dipersepsikan buruk.

Untuk mengukur kinerja karyawan secara individual ada beberapa indikator yang digunakan. Menurut Robbins (2006) ada enam indikator, yaitu:

a. Kualitas

Kualitas kerja diukur dari persepsi karyawa terhadap kualitas pekerjaan yang dihasilkan serta kesempurnaan tugas terhadap keterampilan dan kemampuan karyawan.

b. Kuantitas.

Merupakan jumlah yang dihasilkan dinyatakan dalam istilah seperti jumlah unit, jumlah siklus aktivitas yang diselesaikan.

c. Ketepatan Waktu.

Merupakan tingkat aktivitas diselesaikan pada awal waktu yang dinyatakan, dilihat dari sudut koordinasi dengan hasil output serta memaksimalkan waktu yang tersedia untuk aktivitas lain. 
d. Efektivitas.

Merupakan tingkat penggunaan sumber daya organisasi (tenaga, uang, teknologi, bahan baku) dimaksimalkan dengan maksud menaikkan hasil dari setiap unit dalam penggunaan sumber daya.

e. Kemandirian.

Merupakan tingkat seseorang karyawan yang nantinya akan dapat menjalankan tugas kerjanya.

f. Komitmen kerja.

Merupakan suatu tingkat dimana karyawan mempunyai komitmne kerja dengan instansi dan tanggung jawab karyawan terhadap kantor. Indikator Kinerja menurut Swanson dan Holton yang dikutip oleh Keban (2004:194) mengemukakan bahwa: “kinerja pegawai secara individu dapat dilihat dari apakah misi dan tujuan pegawai sesuai dengan misi lembaga, apakah pegawai menghadapi hambatan dalam bekerja dan mencapai hasil, apakah pegawai mempunyai kemampuan mental, fisik, emosi dalam bekerja, dan apakah mereka memiliki motivasi yang tinggi, pengetahuan, ketrampilan dan pengalaman dalam bekerja. Kinerja dapat diukur dari (1) kuantitas kerja, (2) kualitas kerja, (3) kerjasama, (4) pengetahuan tentang kerja, (5) kemandirian kerja, (6) kehadiran dan ketepatan waktu, (7) pengetahuan tentang kebijakan dan tujuan organisasi, (8) inisiatif dan penyampaian ide-ide yang sehat, (9) kemampuan supervisi dan teknik (Schuler dan Dowling, dalam Keban, 2004:195).

Secara definitif dapat dikatakan bahwa kepuasan konsumen (Basu Swastha, 2000) adalah : "Suatu dorongan keinginan individu yang diarahkan pada tujuan untuk memperoleh kepuasan. Dalam hal ini kita perlu mengetahui bahwa suatu keinginan itu harus diciptakan atau didorong sebelum memenuhi motif. Sumber yang mendorong terciptanya suatu keinginan dapat berbeda dari diri orang itu sendiri atau berada pada 
lingkungannya.

Kotler (2001 : 46) menandaskan bahwa kepuasan konsumen adalah tingkat perasaan seseorang setelah membandingkan kinerja (atau hasil) yang ia rasakan dibandingkan dengan harapannya. Bila kinerja melebihi harapan mereka akan merasa puas dan sebaliknya bila kinerja tidak sesuai harapan maka akan kecewa.

Menurut Irma Nurmazizah (2018) menunjukkan bahwa kinerja pegawai mempunyai pengaruh positif yang signifikan terhadap kepuasan mahasiswa.Lesly Astuti Putri Lubis (2018) menunjukkan bahwa kualitas pelayanan dan kinerja karyawan berpengaruh terhadap kepuasan mahasiswa. Dan menurut Julia Ramdani Nasution (2019) menunjukkan Kualitas Pelayanan berpengaruh positif dan signifikan terhadap kepuasan pelanggan.

\section{METODE PENEL;ITIAN}

Penelitian ini adalah penelitian jenis deskriptif kuantitatif,yang mana penelitian ini bertujuan untuk menggambarkan mengenai sifat-sifat dari suatu keadaan atau objek yang dilakukan melalui pengumpulan data kuantitatif dan pengujian statistik.Pengujian ini bersifat eksploratory dimana pada penelitian ini menggunakan metode sampling atau survei.Jenis data yang digunakan pada penelitian ini ialah data primer dan data sekunder.Kedua jenis data tersebut sangat diperlukan untuk menghitung ketepatan jumlah infomasi yang diperoleh dengan data mengenai variabel-variabel penelitian dan juga data yang dikumpulankan dapat menjadi data yang sederhana sehingga mudah untuk disimpulkan.

Populasi penelitian ini adalah jumlah pendaftar yang melakukan registrasi ulang untuk menjadi mahasiswa baru pada semester Ganjil 2019-2020 sebanyak 6.295 orang,maka jumlah sampel yang diperoleh sebanyak 98 orang yang dihitung dengan menggunakan rumus Slovin Regresi Berganda (Multiple Regresiion Analysis), Uji t ( Parsial), Uji F (Simultan), Koefisien Determinasi.

84 


\section{KERANGKA MODEL PENELITIAN DAN HIPOTESIS}

Kerangka pemikiran adalah suatu diagram yang menjelaskan secara garis besar alur logika berjalannya sebuah penelitian. Kerangka pemikiran dibuat berdasarkan pertanyaan penelitian (research question), dan merepresentasikan suatu himpunan dari beberapa konsep serta hubungan diantara konsep-konsep tersebut (Polancik, 2009).Berdasarkan uraian di atas kerangka model yang digunakan dalam penelitian ini dapat dilihat pada gambar 1 di bawah ini:

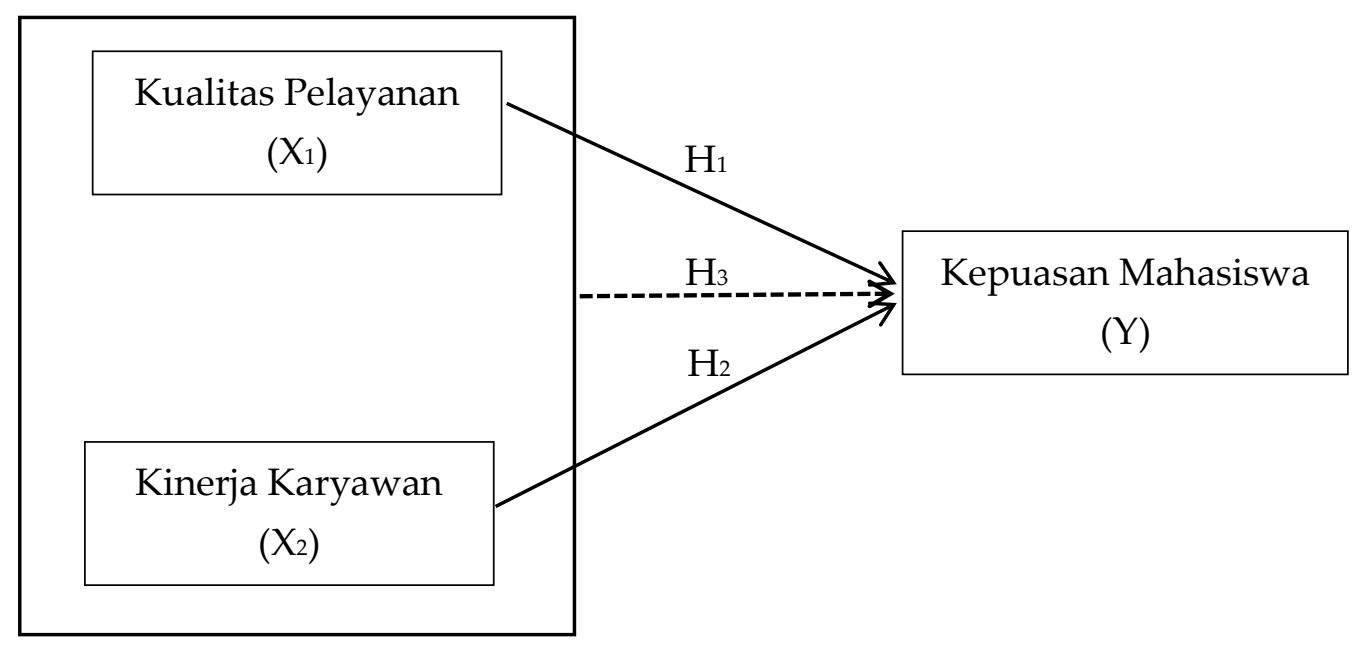

\section{Gambar 1. Kerangka model penelitian}

Keterangan:

: Pengaruh Variabel Secara Parsial

: Pengaruh Variabel $\mathrm{X}_{1}, \mathrm{X}_{2}$, Secara Simultan

\section{HIPOTESIS}

Berlandaskan kerangka model penelitian tersebut diatas, hipotesis dalam penelitian ini adalah sebagai berikut :

H1 : Kualitas Pelayanan berpengaruh positif dan signifikan terhadap Kepuasan mahasiswa. 
H2 : Kinerja Karyawan berpengaruh positif dan signifikan terhadap Kepuasan Mahasiswa.

H3 : Kualitas Pelayanan dan Kinerja Karyawan berpengaruh secara simultan terhadap Kepuasan Mahasiswa.

\section{HASIL PENELITIAN DAN PEMBAHASAN}

\section{Uji Regresi Linear Berganda}

\section{Uji t (Parsial)}

Pengujian hipotesis adalah pengujian terhadap suatu pernyataan dengan menggunakan metode statistik sehingga hasil pengujian tersebut dapat dinyatakan signifikan secara statistik. Hipotesis merupakan pernyataan yang kebenarannya masih lemah. Agar pernyataannya tidak diragukan maka secara statistik kita bisa melakukan pengumpulan data dan melakukan pengujian. Dengan melakukan pengujian statistik terhadap hipotesis kita dapat memutuskan apakah hipotesis dapat diterima (data tidak memberikan bukti untuk menolak) atau ditolak (data memberikan bukti untuk menolak hipotesis).

Tingkat signifikansi $\alpha$ adalah besarnya toleransi yang digunakan dalam menerima kesalahan pengujian secara statistik. Tingkat signifikansi yang sering digunakan adalah, 0,05 dengan menggunakan rumus degree of freedom, $d f=n-k-1=98-2-$ $1=95$,sehinnga di dapat nilai $\mathrm{t}$ tabel sebesar 1,985.

86

Jurnal Komunikasi Bisnis dan Manajemen

Vol. 8 No. 2 Juli 2021 
Tabel 4 Hasil Uji t

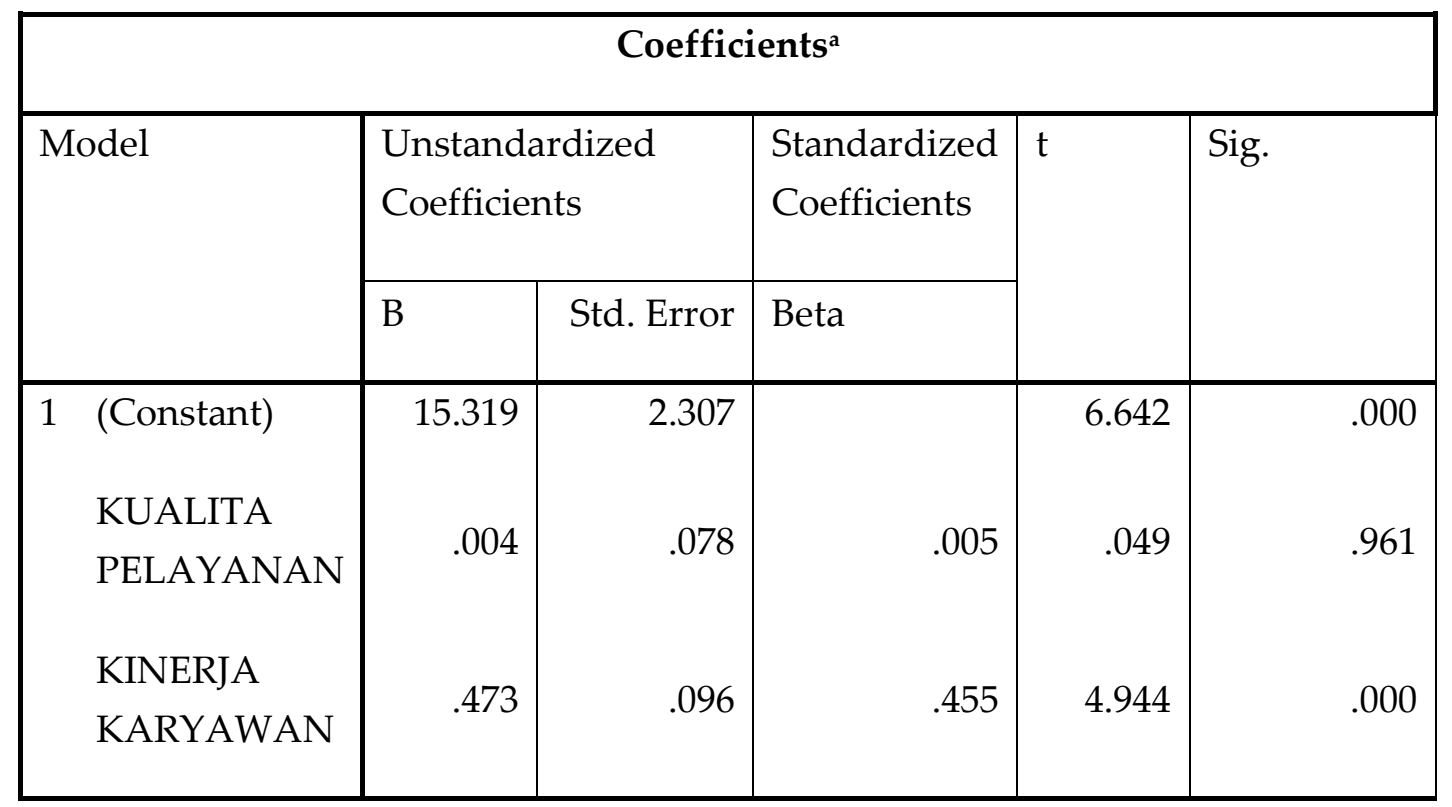

a. Dependent Variable: KEPUASAN MAHASISWA

Sumber:Data diolah SPSS,2020

a) Dari hasil penelitian dapat dilihat pada tabel 4 di atas untuk variabel $\mathrm{X} 1$ (Kualitas Pelayanan) diperoleh nilai t hitung sebesar 0,049<t tabel sebesar 1,985 dengan nilai signifikansi 0,961 >0,005, jadi dapat dikatakan untuk variabel X1 (kualitas pelayanan) berpengaruh positif tetapi tidak signifikan terhadap kepuasan mahasiswa dengan tingkat kesalahan probabilitas variabel sebesar 0,961 (lebih besar dari 0,05). Sehingga dapat disimpulkan untuk H1 yang menyatakan kinerja karyawan secara farsial berpengaruh positif dan signifikan terhadap kepuasan mahasiswa ditolak .

b) Pengaruh variabel X2 (kinerja karyawan) diperoleh nilai t hitung sebesar 4,944 $>1,985$ dengan nilai sign $0,000<0,05$,sehingga dapat dikatakan untuk varibel X2 secara parsial berpengaruh positif dan signifikan.Dengan demikian untuk H2 
yang menyatakan kinerja karyawan berpengaruh positif dan signifikan terhadap kepuasan mahasiswa diterima.

\section{Uji F (Simultan)}

Uji F ini dilakukan untuk melihat variabel independen secara serentak/bersama, berpengaruh signifikan terhadap variabel dependen atau tidak. Uji F digunakan untuk menguji keberartian model regresi yang digunakan. Dengan tingkat signifikansi yang digunakan adalah $\mathrm{a}=5 \% \quad(0,05)$. Rumus yang digunakan yaitu $\mathrm{F}$ tabel=F(K;n$3)=F(2 ; 96)=3,09$

Tabel 5 Hasil Uji F ANOVAa

\begin{tabular}{|l|r|r|r|r|r|}
\hline \multicolumn{1}{|l|}{ Model } & Sum of Squares & df & Mean Square & F & \multicolumn{1}{c|}{ Sig. } \\
\hline 1 Regression & 72.269 & 2 & 36.135 & 12.364 & $.000^{\mathrm{b}}$ \\
Residual & 277.649 & 95 & 2.923 & & \\
Total & 349.918 & 97 & & & \\
\hline
\end{tabular}

a. Dependent Variable: KEPUASAN MAHASISWA

b. Predictors: (Constant), KINERJA KARYAWAN, KUALITA PELAYANAN

Sumber: Data diolah,SPSS 2020

Dari output di atas diperoleh nilai signifikansi untuk pengaruh X1 dan X2 secara simultan terhadap $\mathrm{Y}$ adalah sebesar 0,000<0,05 dan nilai $\mathrm{F}$ hitung 12,978> 3,09,sehingga dapat disimpulkan bahwa H3 diterima yang berarti terdapat pengaruh X1 dan X2 secara simultan terhadap Y.

\section{Analisis Koefisien Diterminasi}

Berdasarkan output pada tabel 3 diketahui nilai R Square sebesar 0,472. Hal ini mengandung arti bahwa pengaruh variabel X1 dan X2 secara simultan terhadap 
variabel Y adalah sebesar 47,2\%,dan sisanya 52,8\% dipengaruhi oleh variabel lain diluar variabel yang diuji penulis.

\section{KESIMPULAN}

Berdasarkan hasil yang diperoleh dari penelitian di atas dapat disimpulkan sebagai berikut:

1. Hasil uji variabel kualitas pelayanan(X1) meskipun berpengaruh positif terhadap kepuasan mahasiswa(Y) tetapi pengaruhnya tidak signifikan.

2. Hasil uji variable kinerja karyawan (X2) berpengaruh terhadap kepuasan mahasiswa.

\section{DAFTAR PUSTAKA}

Anthony, Robert N. dan Vijay Govindaraja.(2009). Sistem Pengendalian Manajemen. Jakarta: Salemba Empat.

A.P.Mangkunegara,2016,Manajemen Sumber Daya Manusia Perusahaan.Bandung:PT.Remaja Rosdakarya.

Bekti Tri Prasetyo. (2014)Analisis Kualitas Pelayanan Terhadap Kepuasan Konsumen Rumah Sakit Moewardi Surakarta. Naskah Publikasi Fakultas Ekonomi Dan Bisnis Universitas Muhammadiyah Surakarta

Gumilar, Rahmat, and Eka Prihatin. "Pengaruh Kepemimpinan Transformasional, Pelatihan, Dan Motivasi Terhadap Kinerja Karyawan Dalam Upaya Meningkatkan Kualitas Pelayanan Administrasi Akademik Di Sekolah Tinggi

Ilmu Ekonomi (STIE) Se-kota Bandung." Jurnal Administrasi Pendidikan UPI, vol. 17, no. 1, Apr. 2013.

Gregor PolanÄ®i $\ddot{A} \odot$, Empirical Research Method Poster, 2007

89

Jurnal Komunikasi Bisnis dan Manajemen

Vol. 8 No. 2 Juli 2021 
Rofiah, C., \& Wahyuni, D. (2017). Kualitas Pelayanan Dan Pengaruhnya Terhadap Loyalitas Pelanggan Yang Di Mediasi Oleh Kepuasan Di Bank Muamalat Jombang. Eksis: Jurnal Riset Ekonomi dan Bisnis, 12(1 Apr).

Supranto, (2011), pengukuran tingkat kepuasan pelanggan untuk menaikan pangsa pasar, Jakarta Rineka Cipta.

Sugiyono.2019,Metode Penelitian Kuantitatif,Kualitatif,dan RED. Bandung. Penerbit: Alfabeta.,

Tri Hani Handoko.2016,Manajemen Personalia dan Sumber Daya manusia,Yogyakarta:BPPE.

Setiawardani, Maya. "Pengaruh Kualitas Pelayanan Administrasi Akademik terhadap Kepuasan Mahasiswa Politeknik Negeri Bandung." Jurnal Riset Bisnis dan Investasi, vol. 4, no. 1, 2018, pp. 40-56, doi:10.35697/jrbi.v4i1.991.

Tjiptono, Fandy. 2001. Strategi Pemasaran. Edisi Pertama. Andi Ofset.Yogyakarta. ___ _ 2007. Strategi Pemasaran. Edisi Pertama. Andi Ofset. Yogyakarta.

Robbins, S.P, 2006, Perilaku Organisasi, Edisi 10, PT. Indeks Kelompok Gramedia

- Keban, Yeremias T (2004), Enam Dimensi Strategis Administrasi Publik Konsep, Teori dan Isu, Gava Media, Yogyakarta. 